\title{
REGIONAL DISTRIBUTION AND ESTRUCTURAL CONTROL OF THE GOLD OCCURRENCES/DEPOSITS IN THE GOIÁS MASSIF AND BRASÍLIA BELT
}

\author{
JOSÉ OSWALDO DE ARAÚJO FILHO \& RAUL MINAS KUYUMJIAN
}

\begin{abstract}
The distribution of gold occurrences/deposits in the GoiÁs Massif and Brasilia Belt reflects the tectonic controls that operated during their geologic evolution. Their distribuiton shows three main regional trends: northwest-southeast, northeast-southwest and north-south, which correspond to tectonic discontinuities generated during the Brasiliano event. Since the regional structural features are an important control for the location of the main gold occurrences/deposits in both massif and belt, further studies of the regional tectonic regime and the establishment of structural models for these geotectonic units are essential to mineral exploration programs for gold in central Brazil.
\end{abstract}

Keywords: gold deposits, distribution, structural control, Goiás

RESUMO Á distribuição das ocorrências/depósitos de ouro no Maciço de Goiás e Faixa Brasília reflete controles tectônicos que aluaram durante a evolucão geológica do maciço e da faixa. Tal distribuicão mostra três tendências regionais: noroeste-sudeste, nordeste-sudoeste e norte-sul, que correspondem a discontinuidades tectônicas geradas durante o evento Brasiliano. Considerando que as feições estruturais regionais são importantes controladores da localização das ocorrências e depósitos de ouro no Maciço de Goiás e Faixa Braś́lia, estudos mais aprofundados sobre regime tectônico regional e o estabelecimento de modelos estruturais para estas unidades geotectônicas são essenciais para o desenvolvimento de programas de exploração para ouro na porção central do Brasil.

Palavras-chaves: depósitos de ouro, distribuição, controle estrutural, Goiás

INTRODUÇÃO A distribuição regional das mineralizações de ouro conhecidas no Maciço de Goiás e na Faixa Brasília reflete, essencialmente, controles tectônicos que atuaram durante a evolução geológica dos mesmos. No entanto, é reduzido o número de trabalhos publicados no sentido de verificar a importância de feições estruturais regionais para explicar a distribuição regional das ocorrências e depósitos de ouro no maciço e na faixa. Dardenne (1982) considera os diferentes tipos de depósitos minerais nos terrenos precambrianos da porção central do Brasil como registros de épocas metalogenéticas distintas, estando as mineralizações auríferas restritas ao Arqueano (greenstone belts) e ao Paleoproterozóico (tipo Witwatersrand). Bernasconi (1985) considera que, embora algumas ocorrências de ouro em veios de quartzo sejam conhecidas nos terrenos granulito gnáissicos da porção central do Brasil, a maioria das mineralizações economicamente importantes estão restritas aos greenstone belts Arqueanos, e sugere que as mesmas são epigenéticas hidrotermais e controladas por feições estruturais. Leonardos et al. $(1988,1991)$ evidenciam que a maioria dos depósitos de ouro em terrenos precambrianos no Brasil está diretamente associada a processos de alteração hidrotermal em estruturas dilatantes de zonas de cisalhamento. Os autores salientam as principais características dos depósitos de ouro em zonas de cisalhamento de alto e baixo ângulos. Radaelli (1992) propõe que o arcabouço estrutural do estado de Goiás é consequência da orogênese Proterozóica denominada Tectônica Superimposta Araxá, cujas estruturas principais tem direções NNESSW e NNW-ESE, às quais as mineralizações auríferas estão relacionadas. Barbosa e Silva (1992) propõem que a influência do lineamento dos Pirineus é marcante na porção sulsudeste do estado de Goiás, repetindo, em escala menor, o mesmo fenómeno em, pelo menos, quatro outras faixas distintas e que correspondem a zonas de cisalhamento de alto ângulo direcionadas $\mathrm{WNW}$, NS e $\mathrm{N} 30^{\circ} \mathrm{W}$. Tais zonas seriam consequência de empurrão de oeste para leste que atuou nas rochas da região durante o Proterozóico, sendo que o linea- mento WNW, que controla mineralizações auríferas, corresponderia a uma rampa lateral, e os outros dois lineamentos seriam fraturas (modelo de Riedel). Estudos em detalhe enfocando mineralizações e depósitos de ouro situados em zonas de cisalhamento regionais no estado de Goiás evidenciam que estruturas menores dilatantes e permeáveis foram fundamentais para a percolação de fluidos e localização de mineralização de ouro (Pulz et al. 1993, Thomson \& Fife 1990, Freitas-Silva et al. 1991).

No presente trabalho, os autores objetivam evidenciar e caracterizar os controles estruturais regionais das mineralizações auríferas no Maciço de Goiás e na Faixa Brasília.

\section{CONTROLE ESTRUTURAL REGIONAL DAS MINE-} RALIZAÇÕES AURÍFERAS Araújo Filho (1980) refere-se à Mega-inflexão dos Pirineus como sendo os lineamentos de direção WNW-SSE mais marcantes no estado de Goiás, atribuindo-lhes um caráter de reativação Meso-Neoproterozóica de grandes lineamentos de falhas herdadas de estruturas anteriores, sugeridas por dados gravimétricos. $\mathrm{O}$ autor considera a repetitividade de lineamentos menores no norte e sul da estrutura como um fenómeno correlato no tempo e semelhante em suas características físicas de quebramento e partição em grandes blocos tectônicos. Mais recentemente, Araújo Filho (1992), complementou a interpretação da Megainflexão dos Pirineus como sendo a parte interna de um cinturão de empurrão e dobramento de antepais (foreland fold-thrust belt), formado no evento Brasiliano do Neoproterozóico como parte do Cinturão Dobrado Brasília. A evolução de tal cinturão correspondeu a dois episódios compressivos distintos, o primeiro, no início do Brasiliano, provocando um transporte tectônico de WNW para ESE, formando estruturas de duplexes. Nestas estruturas, rampas frontais se disporiam espacialmente com direção genérica $\mathrm{N} 10^{\circ} \mathrm{E}$ e, curvando-se em arco com convexidade apontando para $\mathrm{E}$, onde rampas oblíquas gradariam para rampas laterais de médio e alto ângulos formando zonas de cisalhamento com 
direção variável de $\mathrm{N} 50^{\circ} \mathrm{W}$ a $\mathrm{N} 80^{\circ} \mathrm{W}$. Mais superficialmente, numa tectônica frágil, um sistema de fraturamento do tipo Riedel se desenvolveria, sendo também controlador de mineralização. Um segundo episódio compressivo, separado por fase distensiva, pouco intensa, observada no âmbito doforeland fold-thrust belt dos Pirineus, provoca transporte tectônico de NNW para S SE, aproveitando-se de superfícies mecânicas anteriores e gerando foliação superimposta e padrões de interferência de dobras, por interferência de rampas e planos com vergência para S SE, resultando numa nova disposição de zonas de cisalhamento, parcialmente controladas por lineamentos anteriores, onde também se desenvolveriam lineamentos de tipo mega-Riedel, intra-zonais. $\mathrm{O}$ referido episódio cria uma sintaxe estrutural, do ponto de vista geométrico, enquanto que observa-se um curvamento geral da segunda estrutura sugerindo uma origem oroclinal, desenvolvida por existência de obstáculos (butresses), que se traduzem em altos-fundos do substrato do embasamento. Estudos geofísicos posteriores de superfícies Curie (Blum 1995) sugerem a existência de tais obstáculos no mapa de tendências estruturais da sintaxe dos Pirineus.

Radaelli (1992) descreve mais especificamente a existência de blocos tectônicos maiores em Goiás, separados por megazonas de cisalhamento variando estas entre 40 a $120 \mathrm{~km}$ de espaçamento. O sentido do transporte tectônico é semelhante ao da região da mega-inflexão dos Pirineus e portanto, existiria uma tendência à repetitividade de lineamentos na região do Maciço de Goiás (Fig. 1). As megazonas de cisalhamento truncam os cognominados lineamentos Brasilianos e Transbrasilianos, que embora de idades diferentes, poderão estar correlacionados por herança de fragilidade crustal.

Na figura 2 estão diagramados 151 lineamentos a partir do mapa da figura 1 , distinguidos entre lineamentos de idade Meso-Neoproterozóica e Fanerozóica. Verifica-se que existe uma região no diagrama de setor, onde predominam os lineamentos de falhas e juntas, falhas entre $\mathrm{N} 45^{\circ} \mathrm{W}$ a $\mathrm{N} 75^{\circ} \mathrm{W}$ e onde se constatam estar as megazonas de cisalhamento mapeadas, variando entre $\mathrm{N} 55^{\circ} \mathrm{W}$ a $\mathrm{N} 80^{\circ} \mathrm{W}$. Uma outra região, entre $\mathrm{N} 30^{\circ}-50^{\circ} \mathrm{E}$, mostra uma tendência à paralelização de lineamentos proterozóicos e fanerozóicos, sugerindo uma tendência de herança estrutural.

Os traços das falhas de gravidade e traço médio de falhas de empurrão são mostrados na figura 3, predominando as dire-cões $\mathrm{N} 35^{\circ} \mathrm{W}, \mathrm{N} 30^{\circ}-50^{\circ} \mathrm{E}$ e NS. As falhas de gravidade transbrasilianas de direção prevalente $\mathrm{N} 40^{\circ}-50^{\circ} \mathrm{E}$, são interpretadas como reativações de traços de falhas, transcorrentes ou não, de mesma direção. As tendências regionais, contadas por pontos alinhados, das mineralizações estão dispostas na figura 4 , predominando as direções $\mathrm{N} 50^{\circ}-75^{\circ} \mathrm{W}, \mathrm{N} 35^{\circ}-60^{\circ} \mathrm{E}$ e NS.

Os esforços regionais principais durante o Evento Brasiliano, estariam dispostos entre $\mathrm{N} 30^{\circ}-85^{\circ} \mathrm{W}$, gerando mega-zonas de cisalhamento de direção entre $\mathrm{N} 50^{\circ}-75^{\circ} \mathrm{W}$ e $\mathrm{N} 45^{\circ}-60^{\circ} \mathrm{E}$. $\mathrm{O}$ elipsóide de tensão médio com estruturas regionais esquemáticas está mostrado na figura 5.

CONCLUSÃO As mineralizações auríferas no Maciço de Goiás e Faixa Brasília são fenómenos controlados pelo padrão de lineamentos tectônicos da região, onde as zonas de cisalhamento, com suas características estruturais seriam os fatores controladores, por excelência. Assim, a distribuição das ocorrências e depósitos de ouro no maciço apresentam três tendências regionais principais, ou seja, noroeste-sudeste, nordeste-sudoeste e, subordinadamente, norte-sul, as quais correspondem àquelas de descontinuidades tectônicas no maciço, sendo herdadas e geradas no evento tectono-térmico Brasiliano.

Vários aspectos concernentes ao posicionamento e controle estrutural das ocorrências e depósitos de ouro no Maciço de
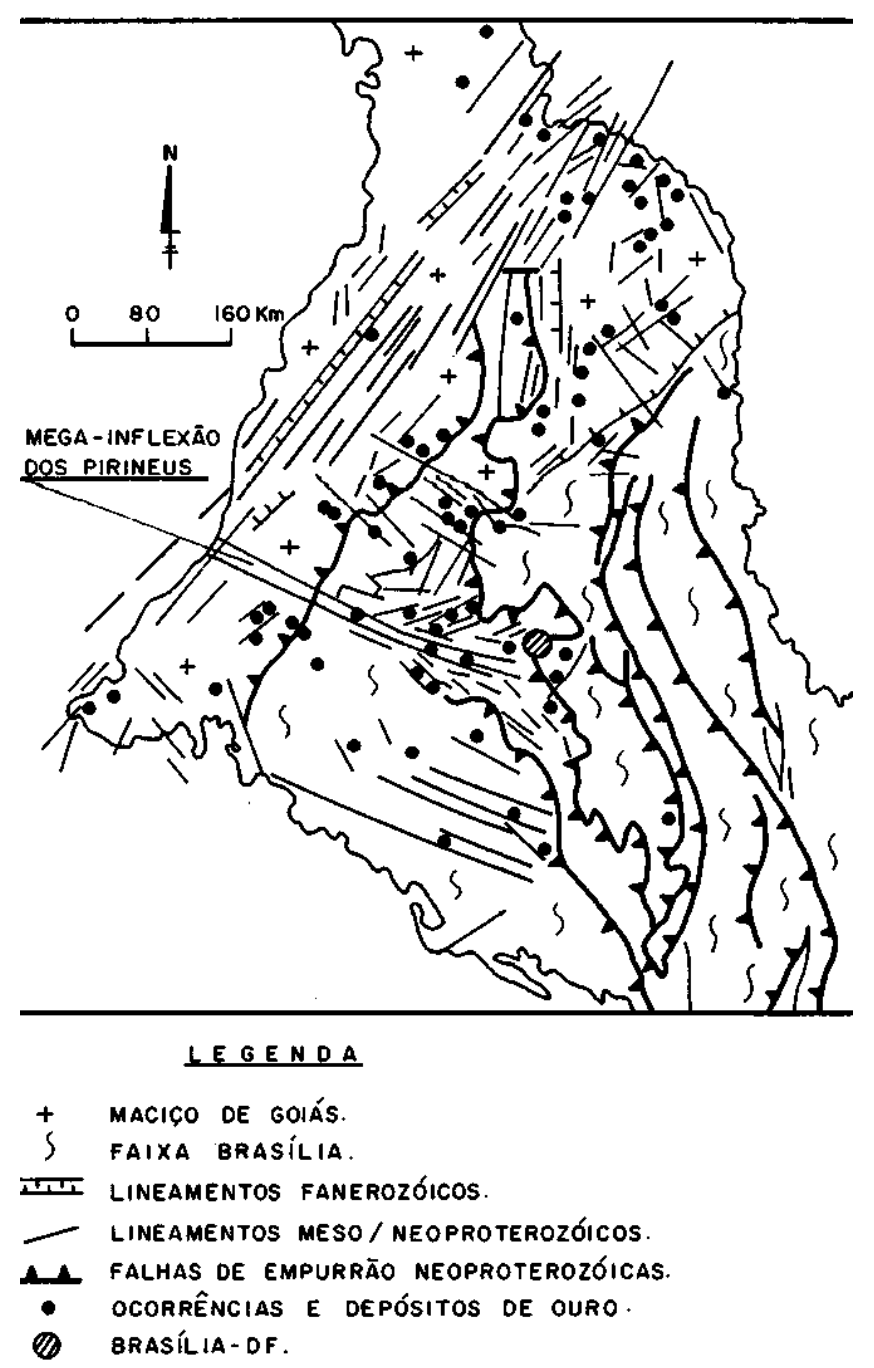

Figura 1 - Mapa regional de lineamentos estruturais do Maciço de Goiás e Faixa Brasília.

Figure 1 - Regional lineaments map of the Goiás Massif and Brasília Belt.

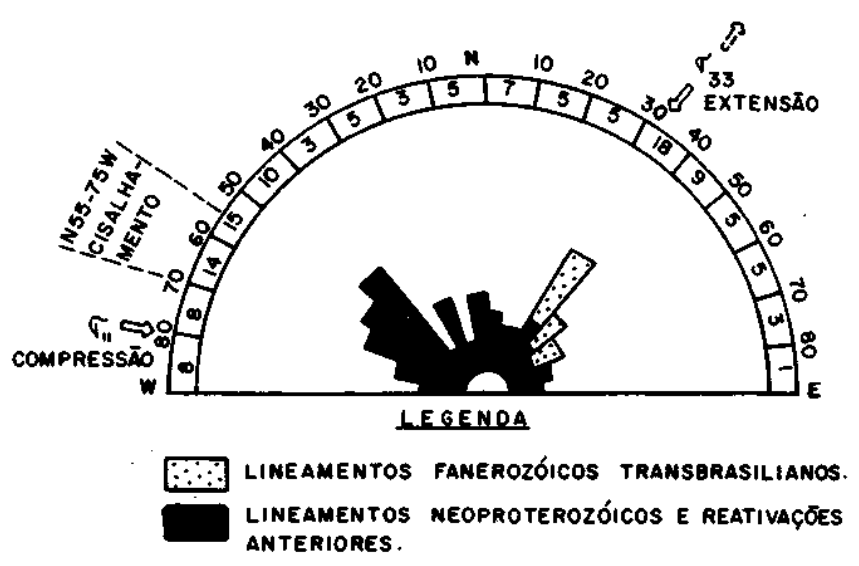

Figura 2 - Diagrama de setor de lineamentos estruturais regionais do Maciço de Goiás e Faixa Brasília. Traços de lineamentos $33 \mathrm{~km}, n=115$.

Figure 2 - Diagram of regional structural lineaments of Goiás Massif and Brasília Belt. Lineament traces 33km, n=115. 


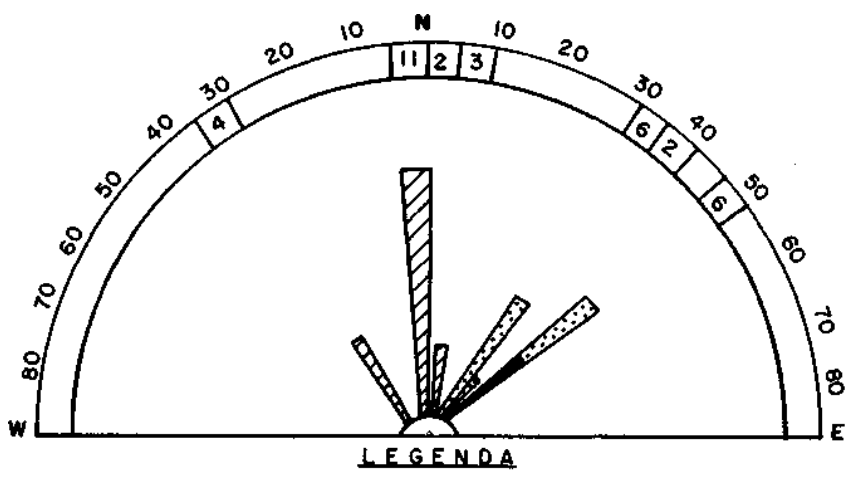

$\because \because$ TRAÇOS oAs falmas de gRaVIDade fanerozólcas.

TRAÇOS DAS FALHAS DE GRAVIDADE NEOPROTEROZÓICA

DZ TRAÇOS MÉdIOS DAS FALHAS EM FORMACĀO NEOPROTE ROzóıCAs.

Figura 3 - Traço das falhas regionais em mapa. Falhas com extensão $33 \mathrm{~km}, n=34$.

Figure 3 - Regional fault traces in map. Faults $33 \mathrm{~km}$ long, $\mathrm{n}=34$.

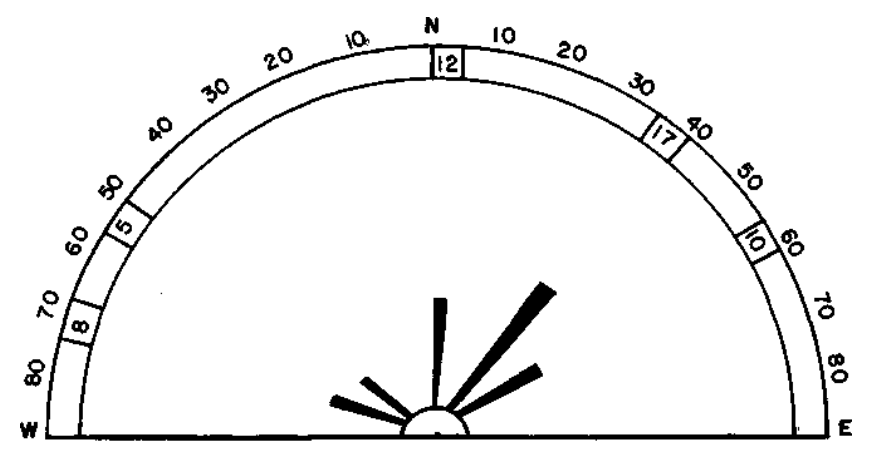

Figura 4 - Tendências principais das mineralizações Figure 4 - Main trends of gold occurrences.

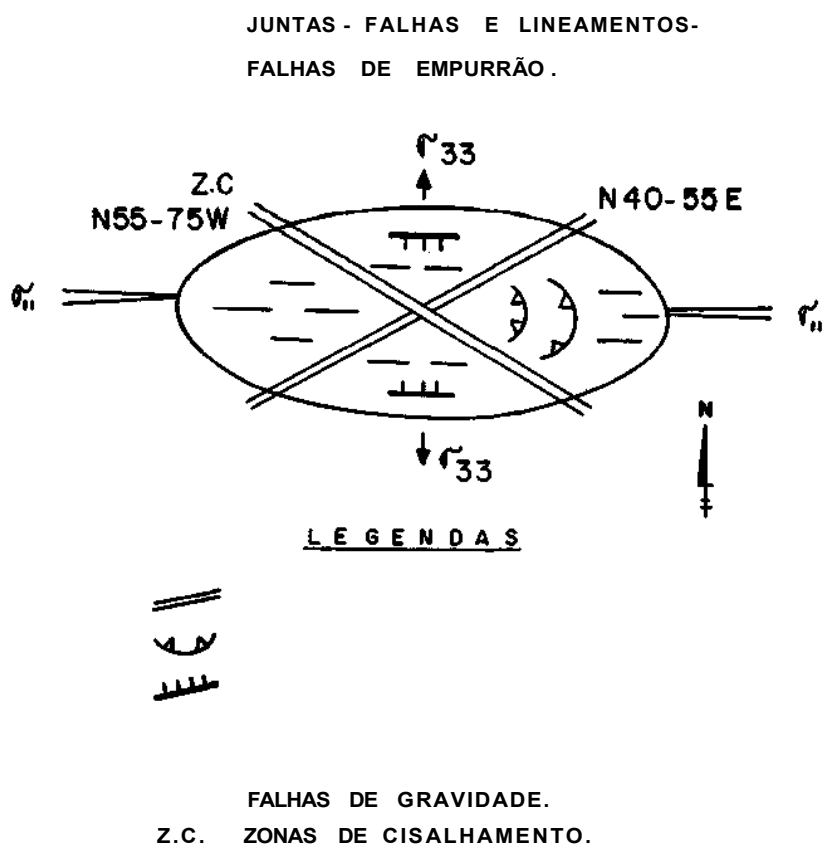

Figura 5 - Elipsóide de tensão genérico para o Maciço de Goiás e Faixa Brasília, durante a deformação Brasiliana, onde as principais estruturas do mapa da figura 1 estão representadas.

Figure 5 - Regional stress ellipsoid for the Goiás Massif and Brasília Belt during the Brasiliano event, where main structures of map of figure 1 are represented.

Goiás e Faixa Brasília necessitam ainda ser pesquisados. Dentre eles, merecem destaque os seguintes: controle estrutural de mineralizações em diferentes domínios metamórficos, evolução petro-estrutural das mega-zonas de cisalhamento, relações geométricas e genéticas entre as mega-zonas de cisalhamento e falhas ou fraturas subsidiárias mineralizadas, diferenças quanto à génese de zonas de cisalhamento mineralizadas e estéreis.

Sendo as feições estruturais regionais um parâmetro importante controlador da localização das principais ocorrências e depósitos de ouro no Maciço de Goiás e Faixa Brasília, o conhecimento cada vez mais aprofundado do regime tectônico regional e o estabelecimento de modelos estruturais no maciço e na faixa, são importantes tanto do ponto de vista académico, como em relação ao desenvolvimento de programas de exploração mineral.

\section{REFERÊNCIAS}

ARAÚJO FILHO, J.O. de 1980. Geology of the Pirineus mega-inflection, Goiás, central Brazil. In: GEO. LATEIN. KOL., 7. Heidelberg, 1980. A/wfracfs...Heidelberg. p. 9-11.

ARAÚJO FILHO, J.O. de 1992. The Pirineus mega-inflection in central Brazil: an example of a poly-deformed Brasiliano fold-thrust belt. In: GEO. LATEIN. KOL., 13. Munster, 1992. Abstracts...Munster. p. 18-19.

BARBOSA, P.A.R. \& SILVA, A. da 1992. Modelo deformacional para o sudeste de Goiás e suas implicações metalogenéticas. In: CONGR. BRÁS. GEOL., 37. São Paulo, 1992. Anais...S\&o Paulo, SBG. v. 2 , p.315.

BERNASCONI, A. 1985. Archaean gold mineralization in central Brazil: a review. Mineral. Deposita, 20:277-283.

BLUM, M. 1995. Superfície Curie da região central de Goiás e relações com geologia, geotectônica e recursos minerais. Brasília. 82 p. (Dissertação de Mestrado, IG/UnB).
DARDENNE, M.A. 1982. Chrono-stratigraphie et metallogenie du Precambrien dans lê Brésil central. In: CONGR. LATINOAM. GEOL., 5, Argentina, 1982. Actas...Argentina, v. 3, p. 65-77.

FREITAS-SILVA, F.H.; DARDENNE, M.A.; JOST, H. 1991. Lithostructural control of the Morro do Ouro, Paracatú, Minas Gerais, gold deposit. In: SYMP. BRAZIL GOLD'91. Balkema, Rotterdam, 1991. Proceedings... Belo Horizonte, p. 681-683.

LEONARDOS, O.H.; JOST, H.; VEIGA, A.T.C. 1988. Brazilian gold districts: how many are not associated with shear zones ? In: Bicentennial Gold 88. Geol. Soe. Austrália, 1988. Abstracts $\mathrm{N}^{\circ} 23$. p. 611-613.

LEONARDOS, O.H.; JOST, H.; OLIVEIRA, C.G. 1991. Gold deposits and shear zone relationships in the Precambrian of Brazil. In: SYMP. BRAZIL GOLD'91. Balkema, Rotterdam, 1991. Proceedings...Belo Horizonte, p. 167-169. 
PULZ, G.M.; JOST, H.; GIULIANI, G.; MICHEL, D. 1993. Evidências mineralógicas e estruturais da percolação episódica de fluidos hidrotermais no depósito aurífero Maria Lázara, Goiás. .An. Acad. Brás. Cí.,65(1): 19-28.

RADAELLI, V.A. 1992. Archean basement structural features overprinted by Araxá Proterozoic Orogeny and related gold, tin and emerald deposits in Goiás. In: CONGR. BRÁS. GEOL., 37. São Paulo, 1992. Anais... São Paulo, SBG. v. 1, p. 223-224.
THOMSON, M.L. \& FIFE, W.S. 1990. The Crixás gold deposit, Brazil; thrust-related post peak metamorphic gold mineralization of possible Brasiliano age. Econ. Geol 85(5):928-942.

MANUSCRITO $\mathrm{n}^{\circ}$ NB-010

Recebido em 10 de abril de 1996

Revisão dos autores em 21 de fevereiro de 1997

Revisão aceita em 22 de fevereiro de 1997 